UCRL-JC-122274

CONFPRINT $9510145-8$

\title{
Chemical Kinetic Modeling of High Pressure Propane Oxidation and Comparison to Experimental Results
}

\author{
NECENE \\ D. N. Koert \\ JA月 15 10.5 \\ W. J. Pitz \\ J. W. Bozzelli \\ OS.TI \\ N. P. Cernansky
}

This paper was prepared for submittal to the

Fall Meeting of Western States Section of the Combustion Institute

Stanford, California

October 30-31, 1995

November 8, 1995

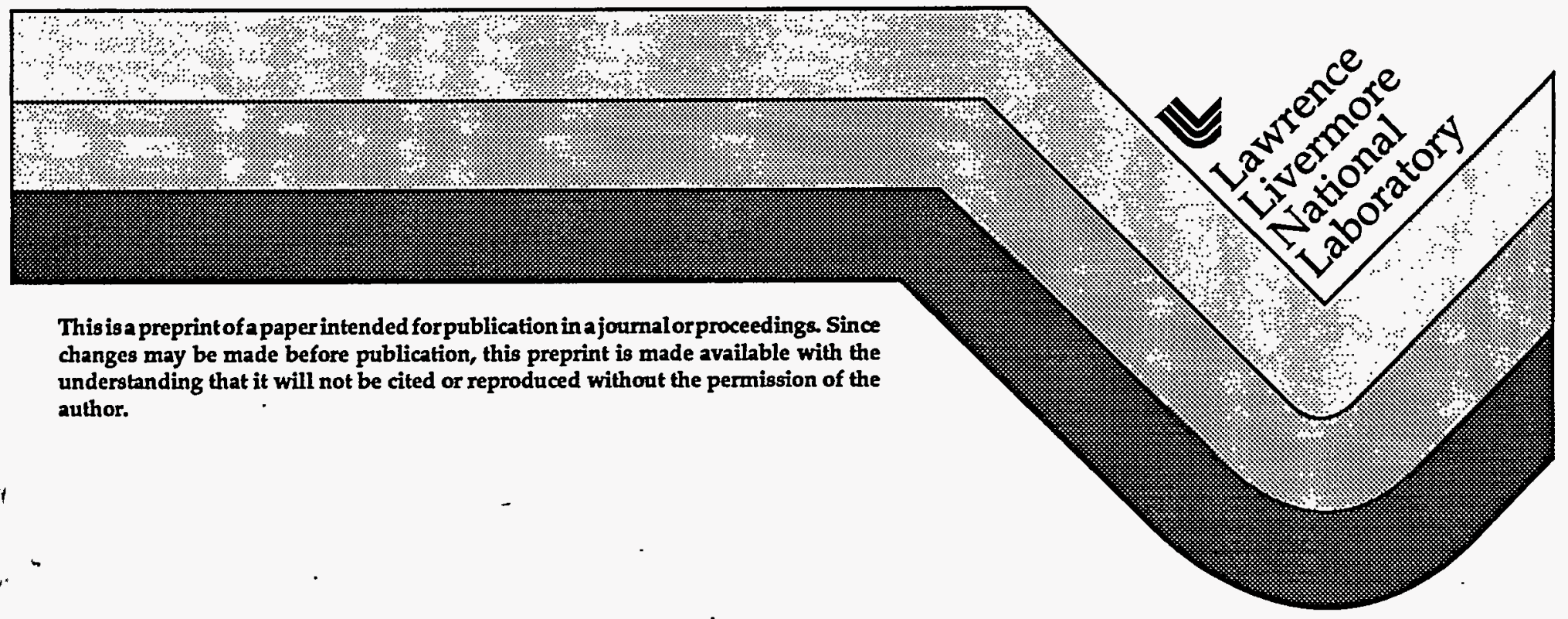




\section{DISCLAIMER}

This document was prepared as an account of work sponsored by an agency of the United States Government. Neither the United States Government nor the University of California nor any of their employees, makes any warranty, express or implied, or assumes any legal liability or responsibility for the accuracy, completeness, or usefulness of any information, apparatus, product, or process disclosed, or represents that its use would not infringe privately owned rights. Reference herein to any specific commercial product, process, or service by trade name, trademark, manufacturer, or otherwise, does not necessarily constitute or imply its endorsement, recommendation, or favoring by the United States Government or the University of California. The views and opinions of authors expressed herein do not necessarily state or reflect those of the United States Government or the University of California, and shall not be used for advertising or product endorsement purposes. 


\title{
Chemical Kinetic Modeling of High Pressure Propane Oxidation and Comparison to Experimental Results
}

\author{
David N. Koert \\ Mechanical Engineering Dept., Wichita State University, Wichita, KS 67260 \\ William J. Pitz \\ Lawrence Livermore National Laboratories, Livermore, CA 94551 \\ Joseph W. Bozzelli \\ Chemistry and Chemical Engineering Department, New Jersey Institute of \\ Technology, \\ Newark, NJ 07102 \\ Nicholas P. Cernansky \\ Depart. of Mechanical Engineering and Mechanics \\ - Drexel University, Philadelphia, PA 19104
}

This paper was prepared for presentation at the

Fall Meeting of Western States Section of the Combustion Institute

Stanford University, Stanford, CA

30-31 October 1995 



\title{
Chemical Kinetic Modeling of High Pressure Propane Oxidation and Comparison to Experimental Results
}

\author{
David N. Koert \\ Mechanical Engineering Dept., Wichita State University, Wichita, KS 67260 \\ William J. Pitz \\ Lawrence Livermore National Laboratories, Livermore, CA 94551 \\ Joseph W. Bozzelli \\ Chemistry and Chemical Engineering Department, New Jersey Institute of \\ Technology, \\ Newark, NJ 07102 \\ Nicholas P. Cernansky \\ Depart. of Mechanical Engineering and Mechanics \\ Drexel University, Philadelphia, PA 19104
}

\section{ABSTRACT}

A pressure dependent kinetic mechanism for propane oxidation is developed and compared to experimental data from a high pressure flow reactor. The experiment conditions range from $10-15 \mathrm{~atm}, 650-800 \mathrm{~K}$, and were performed at a residence time of $200 \mu \mathrm{s}$ for propane-air mixtures at an equivalence ratio of 0.4 . The experimental results include data on negative temperature coefficient (NTC) behavior, where the chemistry describing this phenomena is considered critical in understanding automotive engine knock and cool flame oscillations. Results of the numerical model are compared to a spectrum of stable species profiles sampled . from the flow reactor.

Rate constants and product channels for the reaction of propyl radicals, hydroperoxy-propyl radicals and important isomers with $\mathrm{O}_{2}$ were estimated using thermodynamic properties, with multifrequency quantum Kassel Theory for $k(E)$ coupled with modified strong collision analysis for fall-off.

Results of the chemical kinetic model show an NTC region over nearly the same temperature regime as observed in the experiments. The model simulates properly the production of many of the major and minor species observed in the experiments.

Numerical simulations show many of the key reactions involving propylperoxy radicals are in partial equilibrium at 10-15 atm. This indicates that their relative concentrations are controlled by a combination of thermochemistry and rate of minor reaction channels (bleed reactions) rather than primary reaction rates. Major reactions in partial equilibrium include $\mathrm{C}_{3} \mathrm{H}_{7}+\mathrm{O}_{2}=\mathrm{C}_{3} \mathrm{H}_{7} \mathrm{O}_{2}, \mathrm{C}_{3} \mathrm{H}_{6} \mathrm{OOH}=$ $\mathrm{C}_{3} \mathrm{H}_{6}+\mathrm{HO}_{2}$ and $\mathrm{C}_{3} \mathrm{H}_{6} \mathrm{OOH}+\mathrm{O}_{2}=\mathrm{O}_{2} \mathrm{C}_{3} \mathrm{H}_{6} \mathrm{OOH}$. This suggests that thermodynamic parameters of the oxygenated species, which govern equilibrium concentrations, are important. The modeling results show propyl radical and hydroperoxy-propyl 
radicals reaction with $\mathrm{O}_{2}$ proceeds, primarily, through thermalized adducts, not chemically activated channels.

\section{INTRODUCTION}

The combustion of hydrocarbons in practical combustion devices such as internal combustion (I. C.) engines and gas turbines occurs at pressures well above atmospheric conditions where most experimental flame and thermal reaction studies are conducted. The development and validation of chemical kinetic mechanisms at appropriate pressures are needed to obtain accurate models of fuel oxidation rates in these combustors. These validated reaction mechanisms can then be applied to understand and to predict improvements in problems such as engine knock and hydrocarbon emissions. In this study, a pressure dependent kinetic mechanism for propane oxidation is developed and compared to experimental data from a high pressure flow reactor.

A powerful set of tools were employed to estimate properly thermochemical properties and rate constants at elevated pressures. Thermochemical properties of the stable molecules were estimated using group additivity, bond dissociation increments were used for radicals, with ab initio calculations and isodesmic reaction analysis performed for selected peroxides. Rate constants and product channels for the reaction of propyl radicals, hydroperoxy-propyl radicals and important isomers with $\mathrm{O}_{2}$ were estimated using thermodynamic properties, with multifrequency quantum Kassel Theory for $\mathrm{k}(\mathrm{E})$ coupled with modified strong collision analysis for fall-off. Kinetic estimates include transition state theory (TST) for isomerization reactions with barriers and TST entropies validated from detailed model comparisons to experimental results on ethyl, tertbutyl, isobutenyl and neopentyl radical reactions with $\mathrm{O}_{2}$.

Experimental data from a pressured flow reactor (PFR) were used to validate the chemical kinetic mechanism. The PFR apparatus[1] complements other experimental apparatus (rapid compression machine, motored and fired I. C. engine) for the study of hydrocarbon oxidation related to automotive engine knock. The key advantage of the PRF is that the temperature, pressure and residence time of the fuel-air mixture are all well-characterized and controlled. The temperature history of the fuel-air mixture is maintained at a nearly constant, measured value. In a rapid compression machine or I.C. engine study, the temperature of the fuel-air mixture is time-dependent and usually must be calculated. Also, the effect of walls on the gas-phase chemistry are minimized in the PFR compared to an I.C. engine.

There has been much previous work performed on propane oxidation, but few investigations have been reported in a high pressure flow reactor over the NTC region. One of the unique features of the PFR data [2] used in this study, is that it exhibits a clear and dramatic NTC region from $720-780 \mathrm{~K}$ that was not reported in other flow and stirred reactor studies which focused on higher temperature ranges. Dagaut et al. [3] examined propane oxidation in a jet-stirred reactor at elevated pressures over the temperature range of 900-1200 K. Hoffman et al. [4] performed experiments and modeling of propane oxidation in a flow reactor at 3-6 atm and 850-900K. Cathonnet et al. [5] examined propane oxidation in a flow reactor at $1000 \mathrm{~K}$ and $1-6 \mathrm{~atm}$. These studies were performed at temperatures that exceeded the temperatures of the observed NTC region $(720-780 \mathrm{~K})$ [1]. There have also been 
other propane oxidation studies at lower pressures in an atmospheric flow reactor $[6]$ and static reactors $[7,8]$.

In the following sections of the paper, the development of the chemical kinetic model is described and the experimental technique is documented. The results of the chemical kinetic model are compared to the experimental results. Finally, key findings from the kinetic modeling study are discussed.

\section{CHEMICAL KINETIC MODEL}

The chemical kinetic mechanism was based on previous studies [9], with substantial improvements being made. As will be shown later, many of the important reactions involving alkylperoxy and related species are in partial equilibrium, so that it is essential to address properly the thermodynamic properties of the species that control the equilibrium. The thermodynamic properties (Table 1) for the relevant radicals and stable parents were obtained by group additivity using THERM [10] with updated $\mathrm{H} / \mathrm{C} / \mathrm{O}$ groups and bond dissociation groups [11]. The thermochemical data allow calculation of reverse reaction rate constants by microscopic reversibility.

In this section, the rate constants of the key reactions are discussed. The decomposition of hydrogen peroxide was critical in controlling the location of the end to the NTC region. We used the recent rate evaluation of Marinov et al. [12] which gives a nine parameter, pressure dependent fit. His rate evaluated at the end of the NTC region was slower than Tsang [13] and gave better fit of the end of the NTC region.

The rates of propyl peroxy and hydroperoxy-propyl [14] isomerization are important in controlling the low. temperature chemistry of the NTC region. The activation energies $\left(E_{a}\right)$ for the forward rate of these reactions were estimated by,

$$
\begin{aligned}
& \text { primary } \\
& \mathrm{E}_{\mathrm{a}}=\text { ring strain }+\mathrm{E}_{\mathrm{abst}}\langle\text { secondary }\rangle+\Delta \mathrm{H}_{\mathrm{rxn}}
\end{aligned}
$$

where $\Delta \mathrm{H}_{\mathrm{rxn}}$ is the enthalpy of reaction (only included if reaction is endothermic). The ring strains are $6.0,0.1$, and $6.0 \mathrm{kcal} / \mathrm{mole}$ for rings containing five, six, and seven members respectively [15]. The ring strains were validated with comparisons of modeling and experimental results on the ethyl $+\mathrm{O}_{2}$ reaction system [16]. The activation energy for abstraction ( $\mathrm{E}_{\text {abst }}$ ) was estimated from the reverse reaction (exothermic direction). The reverse reaction is assumed to have an $\mathrm{E}_{\mathrm{abst}}$ which is the same as an alkyl radical abstracting an $\mathrm{H}$-atom from a propylhydroperoxide,

$$
\mathrm{CCCOOH}+\mathrm{R} .=\mathrm{CCCOO} .+\mathrm{RH}
$$

where $\mathrm{R}$ is an alkyl radical. The activation energy of this reaction was estimated from an Evans-Polanyi plot ( $E_{\text {abst }}$ versus $\Delta \mathrm{H}_{\mathrm{rxn}}$ ) [17]) of the similar $\mathrm{H}$-atom abstraction reaction, $\mathrm{RH}+\mathrm{R}^{\prime}=\mathrm{R}$. $+\mathrm{R}^{\prime} \mathrm{H}$. A reduction of $0.3 \mathrm{kcal} / \mathrm{mole}$ in $\mathrm{E}_{\mathrm{abst}}$ for each $\mathrm{kcal} /$ mole reduction in $\Delta \mathrm{H}_{\mathrm{rxn}}$ was obtained.

Pre-exponential factors for the $\mathrm{RO}_{2}$ isomerization were obtained using RADICALC [18], a computer code which implements transition state theory. RADICALC calculates the change in entropy of the radical to the transition state due 
Table I: Thermochemical Properties of Important Species

\begin{tabular}{|c|c|c|c|c|c|c|c|c|}
\hline SPECIES & $\mathrm{Hf}$ & $S$ & Cp 300 & 400 & 500 & 600 & 800 & 1000 \\
\hline $\mathrm{HO} 2$ & 3.80 & 54.73 & 8.44 & 8.94 & 9.43 & 9.90 & 10.75 & 11.45 \\
\hline CH3OO & 4.50 & 65.84 & 13.16 & 15.29 & 17.21 & 18.82 & 21.32 & 23.17 \\
\hline C. $\mathrm{H} 20 \mathrm{OH}$ & 14.80 & 67.53 & 15.83 & 18.22 & 20.23 & 21.82 & 24.03 & 25.39 \\
\hline $\mathrm{CH} 300 \mathrm{H}$ & -31.60 & 65.62 & 15.21 & 18.13 & 20.76 & 22.91 & 26.04 & 28.14 \\
\hline $\mathrm{CCOO}$ & -4.99 & 75.75 & 18.42 & 22.23 & 25.58 & 28.35 & 32.55 & 35.61 \\
\hline C. $\mathrm{COOH}$ & 7.91 & 78.94 & 19.70 & 23.71 & 27.22 & 30.04 & 34.11 & .84 \\
\hline CC. $.0 \mathrm{H}$ & 2.81 & 79.35 & 20.61 & 24.23 & 27.47 & 30.14 & 34.09 & 5.79 \\
\hline $\mathrm{CQ} \cdot \mathrm{CQ}$ & -25.68 & 94.82 & 26.51 & 31.62 & 35.91 & 39.21 & 43.78 & 5.65 \\
\hline$C . Q C Q$ & -17.88 & 98.42 & 28.70 & 33.62 & 37.80 & 41.00 & 45.32 & 7.83 \\
\hline $\mathrm{CCOOH}$ & -41.09 & 75.53 & 20.47 & 25.07 & 29.13 & 32.44 & 37.27 & 40.58 \\
\hline CQCQ & -61.78 & 94.60 & 28.56 & 34.46 & 39.46 & 43.30 & 48.50 & 51.62 \\
\hline C. $\mathrm{CCOOH}$ & 2.98 & 89.74 & 25.20 & 30.66 & 35.47 & 39.39 & 45.18 & 49.18 \\
\hline $\mathrm{CC} . \mathrm{COOH}$ & .33 & 89.39 & 24.47 & 29.69 & 34.28 & 38.40 & 44.59 & 48.47 \\
\hline $\mathrm{CCC} . \mathrm{OOH}$ & -2.12 & 88.77 & 26.11 & 31.18 & 35.72 & 39.49 & 45.16 & 49.13 \\
\hline $\mathrm{CCCOO}$ & -9.92 & 85.17 & 23.92 & 29.18 & 33.83 & 37.70 & 43.62 & 47.95 \\
\hline $\mathrm{C} 2 \mathrm{COO}$ & $-12 \cdot 48$ & 82.30 & 24.04 & 29.58 & 34.35 & 38.21 & 44.00 & 48.18 \\
\hline $\mathrm{C} 2 . \mathrm{COOH}$ & .42 & 86.88 & 25.32 & 31.06 & 35.99 & 39.90 & 45.56 & 49.41 \\
\hline $\mathrm{C} 2 \mathrm{C} . \mathrm{OOH}$ & -7.08 & 88.06 & 26.31 & 31.11 & 35.45 & 39.09 & 44.59 & 48.53 \\
\hline $\mathrm{CQ} \cdot \mathrm{CCQ}$ & -30.61 & 104.24 & 32.01 & 38.57 & 44.16 & 48.56 & 54.85 & 58.99 \\
\hline $\mathrm{CQC} \cdot \mathrm{CQ}$ & $-20 \cdot 36$ & 108.46 & 32.56 & 39.08 & 44.61 & 49.26 & 55.82 & 59.51 \\
\hline C. QCCQ & -22.81 & 107.84 & 34.20 & 40.57 & 46.05 & 50.35 & 56.39 & 60.17 \\
\hline $\mathrm{CCQ} \cdot \mathrm{CQ}$ & -32.37 & 101.38 & 32.13 & 38.97 & 44.68 & 49.07 & 55.23 & 59.22 \\
\hline CCQCQ. & -32.37 & 101.38 & 32.13 & 38.97 & 44.68 & 49.07 & 55.23 & 59.22 \\
\hline C. CQCQ & -19.47 & 105.95 & 33.41 & 40.45 & 46.32 & 50.76 & 56.79 & 60.45 \\
\hline $\mathrm{CC} \cdot \mathrm{QCQ}$ & -26.97 & 107.14 & 34.40 & 40.50 & 45.78 & 49.95 & 55.82 & 59.57 \\
\hline $\mathrm{CCQC} \cdot \mathrm{Q}$ & -24.57 & 104.98 & 34.32 & 40.97 & 46.57 & 50.86 & 56.77 & 60.40 \\
\hline $\mathrm{CCCOOH}$ & -46.02 & 84.95 & 25.97 & 32.02 & 37.38 & 41.79 & 48.34 & 52.92 \\
\hline $\mathrm{C} 2 \mathrm{COOH}$ & -48.58 & 82.08 & 26.09 & 32.42 & $: 37.90$ & 42.30 & 48.72 & 53.15 \\
\hline CQCCQ & -66.71 & 104.02 & 34.06 & 41.41 & 47.71 & 52.65 & 59.57 & 63.96 \\
\hline CCQCQ & -68.47 & 101.16 & 34.18 & 41.81 & 48.23 & 53.16 & 59.95 & 64.19 \\
\hline$C C \star O C Q$ & -71.31 & 90.93 & 27.09 & 31.89 & 35.96 & 39.55 & 45.48 & 49.99 \\
\hline $\mathrm{CCQC} * \mathrm{O}$ & -67.63 & 89.37 & 26.80 & 32.56 & 37.44 & 41.14 & 46.93 & 51.18 \\
\hline $\mathrm{CQCC} * \mathrm{O}$ & -65.46 & 92.21 & 26.63 & 31.70 & 36.14 & 39.96 & 45.85 & 50.28 \\
\hline
\end{tabular}

Notes:

$Q$ denotes $\mathrm{OOH}$, * denotes phi bond, dot denotes radical site on left-adjacent carbon atom.

Units: Temperature, $\mathrm{K} ; \mathrm{Hf}, \mathrm{kcal} / \mathrm{mole} ; \mathrm{S}$ and $\mathrm{Cp}(\mathrm{T})$, cal/mol-K. 
to loss or gain of internal rotors, of specific vibrations and of optical isomers. Results of the calculations show that the loss of internal rotors is the major contribution to the loss of entropy and thus reduction in Arrhenius pre-exponential factor for these $\mathrm{H}$-atom transfer reactions. The pre-exponential factors show a decrease with increasing size of the molecule in this mass range due to the increase in moments of inertia of the rotors which are tied up in the transition state. The rates constants of $\mathrm{RO}_{2}$ isomerization are given in Table II.

$$
\begin{gathered}
\text { Table II: } \mathrm{RO}_{2} \text { Isomerization Rate Constants }\left(\mathrm{RO}_{2}=>\mathrm{R}^{\prime} \mathrm{OOH}\right) \\
\left(\mathrm{k}=\mathrm{AT}^{\mathrm{N}} \exp \left(-\mathrm{E}_{\mathrm{a}} / \mathrm{RT}\right) \text {, rate per } \mathrm{H} \text { atom }\right)
\end{gathered}
$$

\begin{tabular}{|c|c|c|c|c|c|}
\hline Ring Size & Site & $\begin{array}{c}\mathrm{A} \\
{\left[\mathrm{sec}^{-1}\right]}\end{array}$ & $\mathrm{N}$ & $\begin{array}{c}\mathrm{E}_{\mathrm{a}} \\
{[\mathrm{kcal} / \mathrm{mole}]}\end{array}$ & $\mathrm{RO}_{2}$ \\
\hline \multirow[t]{2}{*}{5} & primary & $1.29 \mathrm{E}+09$ & 1 & 28.8 & $\mathrm{C}_{2} \mathrm{COO}$. \\
\hline & secondary & $5.70 \mathrm{E}+08$ & 1 & 26.7 & cccoo. \\
\hline 6 & primary & $4.54 \mathrm{E}+07$ & 1 & 22.9 & CCCOO. \\
\hline
\end{tabular}

Rate constants and product channels for the reaction of propyl and hydroperoxy-propyl radicals with $\mathrm{O}_{2}$ were estimated using multifrequency quantum Kassel Theory $[19,20]$ for $k(E)$ coupled with modified strong collision analysis for fall-off.

The numerical model assumed constant temperature and pressure, and plug flow in the flow reactor experiments.

\section{EXPERIMENTAL TECHNIQUE}

The Pressured Flow Reactor (PRF) has been described previously [2] and is briefly given here. A $2.5 \mathrm{~cm}$ diameter Vycor reactor is housed in a stainless steel pressure vessel. Reactant gases are metered with mass flow controllers. The experiments covered a range from $650-850 \mathrm{~K}$ and pressures of 5 and $10 \mathrm{~atm}$. Propane/air mixtures were maintained at an equivalence ratio of 0.4 . The initial concentration of propane and oxygen was the same in each experiment $\left(2.47 \mathrm{~mol} / \mathrm{m}^{3}\right.$ at $800 \mathrm{~K}$ ), with the balance of the flow consisting entirely of nitrogen.

Samples of the reacting gases were withdrawn with a glass-lined, water-cooled gas sampling probe. Samples were extracted at constant residence time $(198 \mathrm{~ms})$ at different reactor temperatures by adjusting the axial position of the sampling probe during the experiment. Samples were analyzed on a Varian 3740 gas chromatograph (GC) with a Porapak $Q$ column followed by a Porapak $N$ column and a flame ionization detector (FID). A postcolumn heated catalyst consisting of powder nickel was used to methanize the oxides of carbon to increase the sensitivity of the measurement by FID.

\section{RESULTS}

The results of the numerical model are compared to the experimentally measured results in Figs. 1-3. Figure 1 shows the propane consumption across the NTC region at 10 and $15 \mathrm{~atm}$. Both the model and experiments show a distinct NTC 
region. The characteristic shape of the profiles is well reproduced by the model. The modeling results do not exhibit the nearly complete lack of fuel consumption seen in the experiments at around 780K.

The intermediate species profiles are shown in Figs. 2 and 3. The measured and calculated carbon monoxide profiles agree quite well. The calculated peak of the propene profile is slightly low at $10 \mathrm{~atm}$ and in excellent agreement at $15 \mathrm{~atm}$. The predicted maximum concentration of formaldehyde is 3.5 times high at $10 \mathrm{~atm}$ and a factor of 15 high at $15 \mathrm{~atm}$ compared to the measured values. The acetaldehyde peak concentration is a factor of $3 \mathrm{high}$ at $10 \mathrm{~atm}$ and $15 \mathrm{~atm}$ compared to the measured concentration. The carbon dioxide profiles are in good agreement at both pressures.

A number of minor species were measured and compared to calculated values. Methanol is predicted to be a factor of 5 higher than observed in the experiments. The calculated maximum concentration of acrolein is about 20 times higher than the measured maximum. The concentrations of propionaldehyde, acetone and propene oxide are all predicted to be at the same order of magnitude as in the experiments.

Analysis of the reaction paths from the numerical simulations show many interesting features. Several key reactions are in partial equilibrium so that their relative concentrations are controlled by thermochemistry. These major reactions include the addition of propyl and hydroperoxy-propyl to $\mathrm{O}_{2}$ :

$$
\begin{aligned}
& \mathrm{C}_{3} \mathrm{H}_{7}+\mathrm{O}_{2} \leftrightarrow \mathrm{C}_{3} \mathrm{H}_{7} \mathrm{O}_{2} \\
& \mathrm{C}_{3} \mathrm{H}_{6} \mathrm{OOH}+\mathrm{O}_{2} \leftrightarrow \mathrm{O}_{2} \mathrm{C}_{3} \mathrm{H}_{6} \mathrm{OOH} .
\end{aligned}
$$

Careful estimation of thermodynamic parameters for the species in these reactions was important to achieve the proper partial equilibrium. Additionally, thermochemistry was important in controlling the production rate of propene:

$$
\text { C. } 3 \mathrm{H}_{6} \mathrm{OOH} \leftrightarrow \mathrm{C}_{3} \mathrm{H}_{6}+\mathrm{HO}_{2}
$$

Reverse rates computed from thermochemistry were $10-15 \%$ of the forward rates.

One key issue addressed in this study are chemically-activated reactions involving the addition of propyl and hydroperoxy-propyl radicals to molecular oxygen. In the case of propyl radicals, addition leads to the products propene and $\mathrm{HO}_{2}$. The most rapid rate was found at the end of the NTC region $(770-780 \mathrm{~K})$ where $10 \%$ of the propene is produced by the chemically activated path,

$$
\mathrm{C}_{3} \mathrm{H}_{7}+\mathrm{O}_{2} \rightarrow \mathrm{C}_{3} \mathrm{H}_{6}+\mathrm{HO}_{2} \text {. }
$$

The remaining $90 \%$ of the propene is produced through stabilized adducts (Reaction 1). In the case of hydroperoxy-propyl addition to molecular oxygen, the chemicallyactivated paths contribute less than $0.5 \%$ of the overall addition process. Almost all the molecular addition occurs through stabilized adducts:

$$
\text { C. }{ }_{3} \mathrm{H}_{6} \mathrm{OOH}+\mathrm{O}_{2} \leftrightarrow \mathrm{O}_{2} \mathrm{C}_{3} \mathrm{H}_{6} \mathrm{OOH} \rightarrow \text { products }
$$

Modeling results for the consumption of the adduct $\mathrm{O}_{2} \mathrm{C}_{3} \mathrm{H}_{6} \mathrm{OOH}$ revealed a new consumption path. The adduct can react by two paths, the first of which (Reaction 2) is frequently mentioned in the literature [21]:

$$
\begin{aligned}
. \mathrm{OOCCCOOH} & \rightarrow \mathrm{HOOCCC}=\mathrm{O}+\mathrm{OH} \\
& \rightarrow \mathrm{HOOCC} . \mathrm{COOH} \rightarrow \mathrm{C}=\mathrm{CCOOH}+\mathrm{HO}_{2}
\end{aligned}
$$

(The carbon atoms are assumed to be fully saturated with $\mathrm{H}$ atoms, the dot indicates a radical site on the left, adjacent carbon atom. The above example shows the 
consumption of one of the three possible $\mathrm{O}_{2} \mathrm{C}_{3} \mathrm{H}_{6} \mathrm{OOH}$ isomers). The second path (Reaction 3) involves abstraction of the $\mathrm{H}$ atom from the non-oxygenated carbon and has been noted recently [19]. The present calculations show that Reaction 3 accounts for 5-30\% of the consumption of the $\mathrm{O}_{2} \mathrm{C}_{3} \mathrm{H}_{6} \mathrm{OOH}$ adducts at the start of the NTC region, with the rest being consumed by Reaction 2 . Reaction 2 accelerates the oxidation process because it produces a reactive $\mathrm{OH}$ radical while Reaction 3 produces a relatively unreactive $\mathrm{HO}_{2}$ radical. Therefore, it is important to include the newly-considered path (Reaction 3 ) to achieve the proper overall rate for propane oxidation.

\section{CONCLUSIONS}

High pressure flow reactor experiments were simulated with a newly developed mechanism for propane oxidation. In the mechanism development, the thermodynamic parameters of the peroxy and hydroperoxy $\mathrm{C}_{3}$ species were carefully estimated. These properties controlled the partial equilibrium of key reactions involving the addition of propyl and hydroperoxy-propyl to molecular oxygen. Chemically-activated reaction paths associated with these additions were also estimated by $Q R R K$ analysis. In the case of propyl addition to $\mathrm{O}_{2}$, the chemically activated reaction paths contributed to about $10 \%$ of the propene production at the end of the NTC region. In the case of hydroperoxy-propyl addition to $\mathrm{O}_{2}$, the chemically activated paths contributed less than $0.5 \%$, with almost all the addition proceeding through stabilized adducts. These results indicate that for propane oxidation at 10 ant 15 atm across the NTC region, these chemically activated paths make a minor contribution.

\section{ACKNOWLEDGMENTS}

The authors greatly appreciate valuable discussions with Henry Curran and Nick Marinov of Lawrence Livermore National Laboratory. The experimental work at Drexel University was carried out under ARO contract No. DAAH04-93-G-0042 and NSF grant no. CTS 9213501. The portion of this work at Wichita State University was funded by the National Institute for Aviation Research. The work at LLNL was carried out under the auspices of the U. S. Department of Energy by the Lawrence Livermore National Laboratory under contract No. W-7405-ENG-48. 


\section{REFERENCES}

1. Koert, D.N. and Cernansky, N.P., Meas. Sci. Technol. (formerly J. Phys. E) 3:607613, 1992.

2. Koert, D.N., Miller, D.L. and Cernansky, N.P. Combust. Flame 96:34-49 (1994).

3. Dagaut, P., Cathonnet, M., Boettner, J.C., and Gaillard, F. Combust. Sci. and Tech. 56:23-63 (1987).

4. Hoffman, J.S., Lee, W., Litzinger, T. A., Santavicca, D. A., and Pitz, W. J., Combust. Sci. Technol. 77:95 (1991).

5. Cathonnet, M., Boettner, J.C., and James, H., Eighteenth Symposium (International) Combustion, The Combustion Institute, Pittsburgh, 1981, p. 903.

6. Westbrook, C. K. and Pitz, W. J. Combust. Sci. and Tech., 37:117. (1984).

7. Wilk, R. D., Cernansky, N. P., and Cohen, R. S. Combust. Sci. and Tech., 49:41-78 (1986).

8. Baker, R. R., Baldwin, R. R., and Walker, R. W., Trans. Faraday Soc. 66:30163031. (1970).

9. Pitz, W. J., Westbrook, C. K., and Leppard, W. R., "Autoignition Chemistry of $\mathrm{C}_{4}$ Olefins Under Motored Engine Conditions: A Comparison of Experimental and Modeling Results," SAE Transactions, SAE paper SAE-912315 (1991).

10. Ritter, E. R. and Bozzelli, J. W. Int. J. Chem. Kinet. 23:767(1991).

11. Lay, T., and Bozzelli, J. W. Chemical and Physical Processes in Combustion, The Eastern States Section Meeting of the Combustion Institute, Paper \#100 (1-4), 1993.

12. Nick Marinov, N. M. and Malte, P. C. Int. J. Chem. Kin. 27:957 (1995).

13. Tsang, W., and Hampson, R.F. J. Phys. Chem. Ref. Data 15:1087-1279 (1986).

14. Bozzelli, J.W. and Pitz, W.J. Twenty-Fifth International Symposium on Combustion, The Combustion Institute, Pittsburgh, PA, 1994, p. 783-791.

15. Dorofeeva, O. V., Gurvich, L. V., and Jorish, V. S. J. Phys. Chem. Ref. Data 15:437-464 (1986). 
16. Bozzelli, J.W., and Dean, A.M. J. Phys. Chem. 94:3313 (1990).

17. Evans, M. G. and Polanyi, M. Trans. Faraday Soc. 34:11 (1938).

18. Bozzelli, J. W., Ritter, E. R., Chemical and Physical Processes in Combustion, The Combustion Institute, Pittsburgh, PA, 1993, \#103, p. 459.

19. Dean, A. M., J. Phys. Chem. 89:4600 (1985).

20. Dean, A. M., Bozzelli, J. W., Ritter, J. W. Combust. Sci. Tech. 80:63-85 (1991).

21. Benson, S. W. Prog. Energy Combust. Sci. 7:125-134 (1981).

\section{FIGURE CAPTIONS}

Figure 1. Comparison of the experimental and calculated fuel consumed: A. 10 atm. B. $15 \mathrm{~atm}$

Figure 2. Comparison of the experimental and calculated species concentrations at $10 \mathrm{~atm}$.

Figure 3. Comparison of the experimental and calculated species concentrations at $15 \mathrm{~atm}$. 

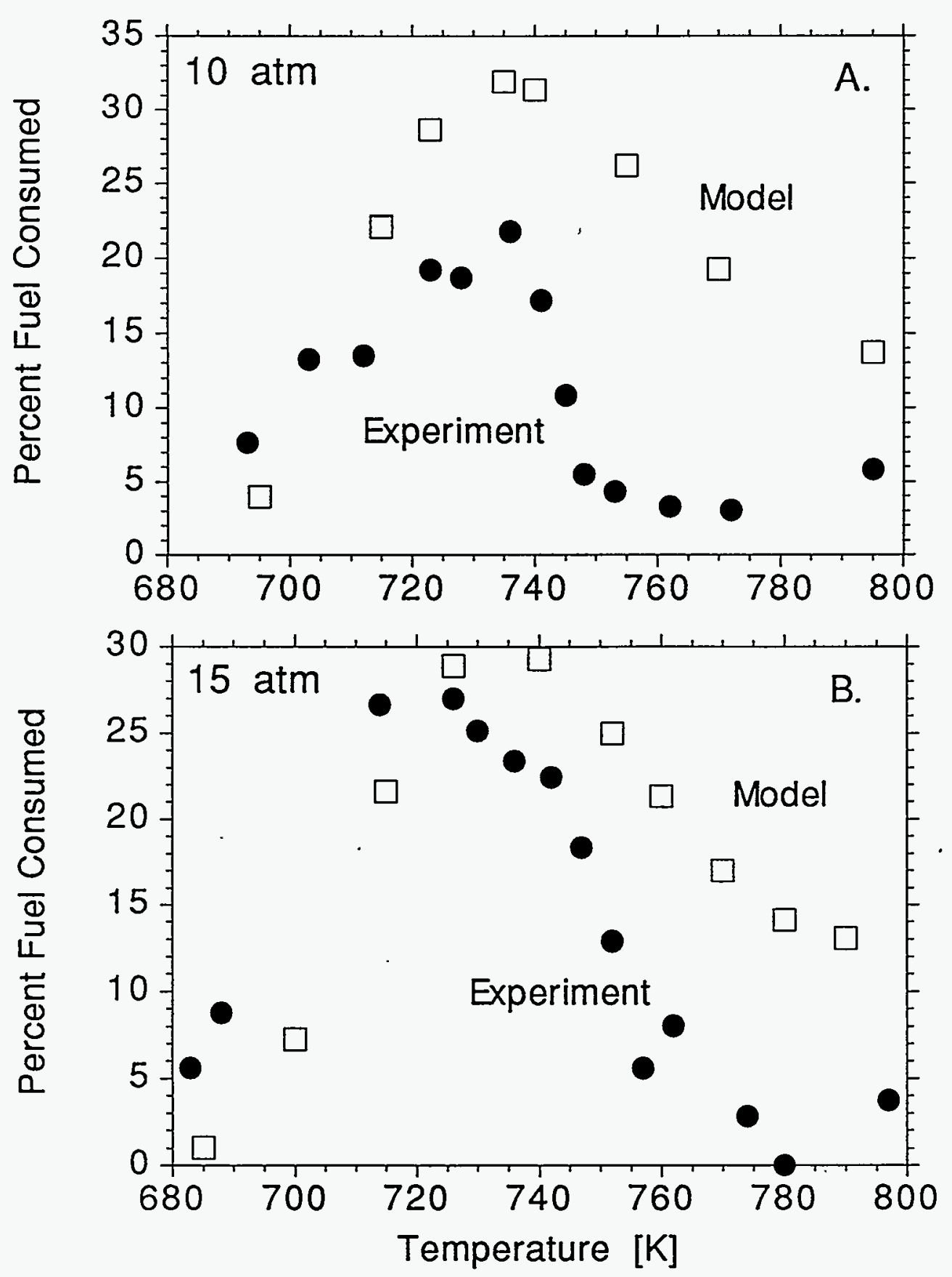

Figure 1. Comparison of the experimental and calculated fuel consumed:

A. $10 \mathrm{~atm}$. B. $15 \mathrm{~atm}$ 


\section{$10 \mathrm{~atm}$}
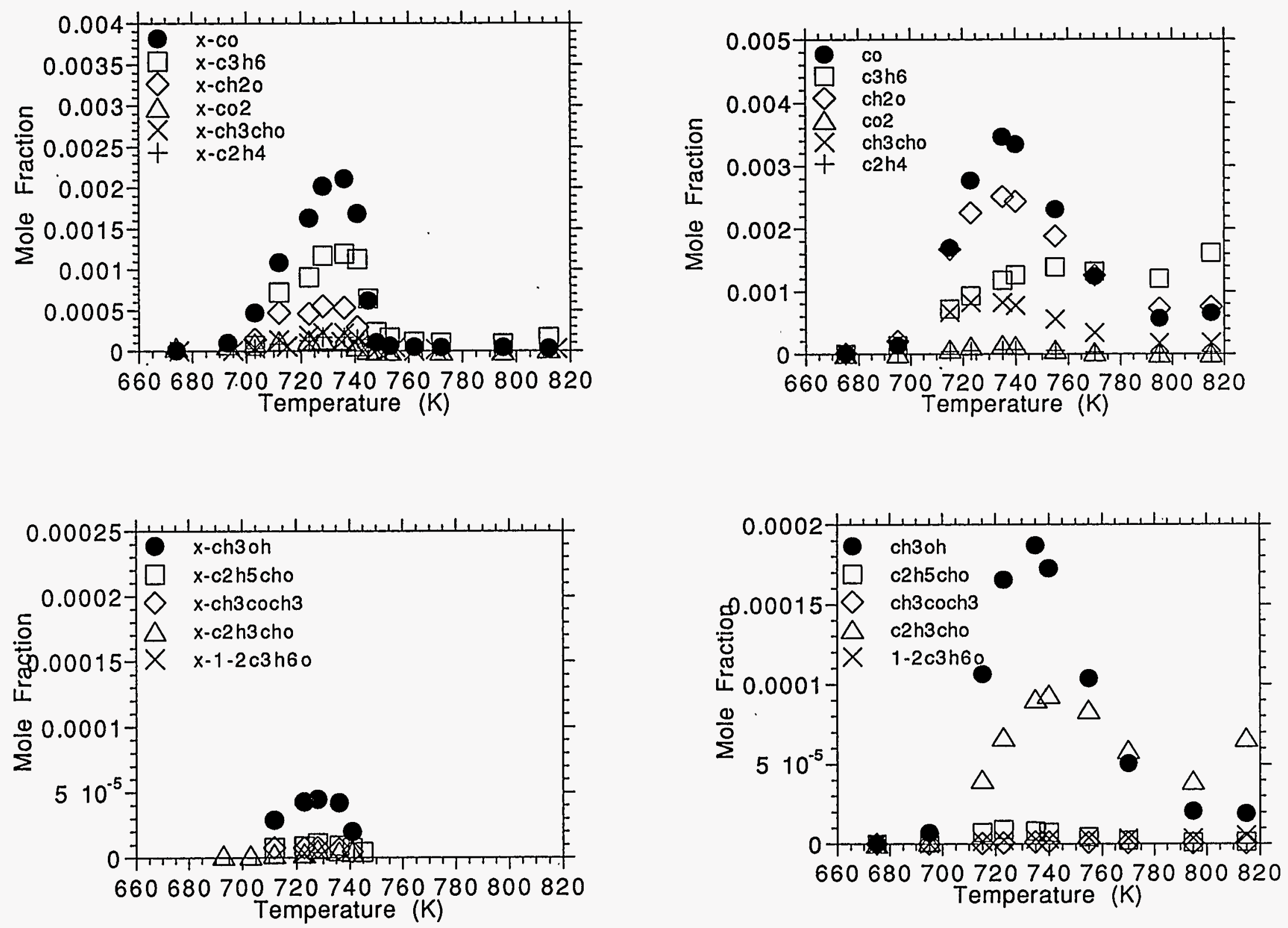

Figure 2 


\section{5 atm}
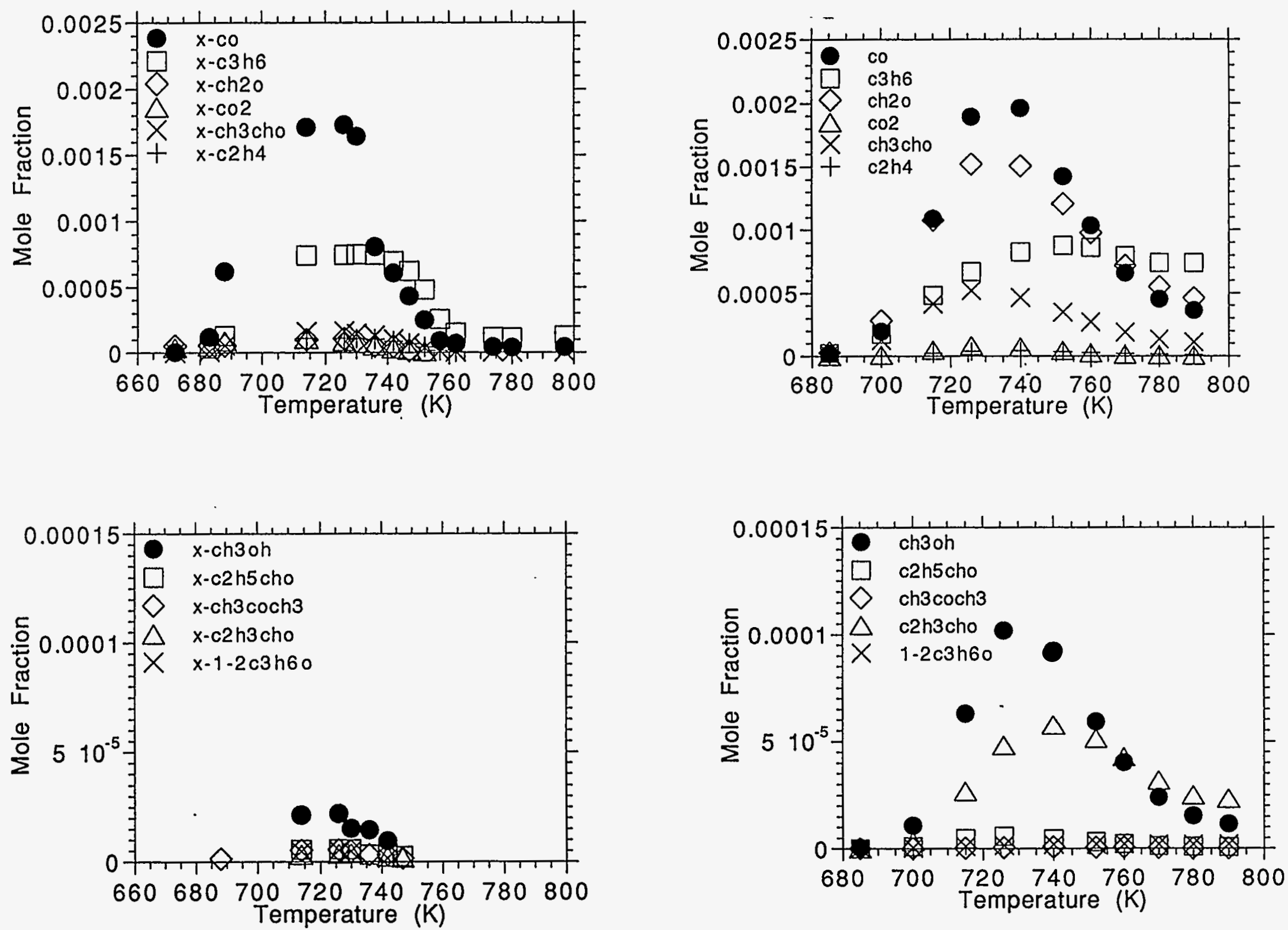

Figure 3 
Technical Information Department . Lawrence Livermore National Laboratory University of California - Livermore, California 94551

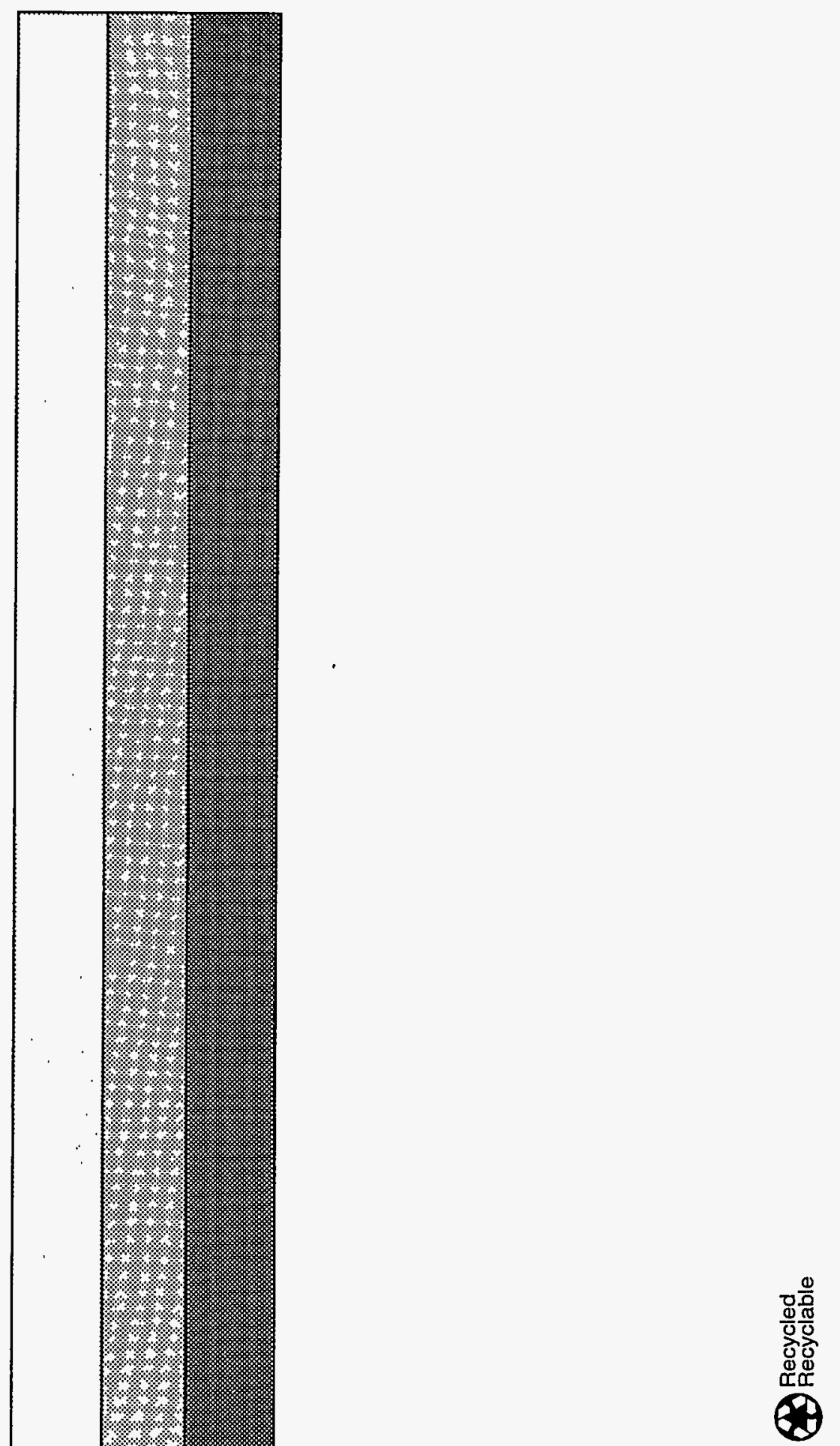

